\title{
Article
}

\section{A changing culture? Qualitative methods teaching in U.K. psychology}

Gibson, Stephen and Sullivan, Cath

Available at https://clok.uclan.ac.uk/24942/

Gibson, Stephen and Sullivan, Cath orcid iconORCID: 0000-0001-5417-8945

(2018) A changing culture? Qualitative methods teaching in U.K. psychology. Qualitative Psychology, 5 (2). pp. 197-206. ISSN 2326-3598

It is advisable to refer to the publisher's version if you intend to cite from the work. http://dx.doi.org/10.1037/qup0000100

For more information about UCLan's research in this area go to

http://www.uclan.ac.uk/researchgroups/ and search for < name of research Group>.

For information about Research generally at UCLan please go to http://www.uclan.ac.uk/research/

All outputs in CLoK are protected by Intellectual Property Rights law, including Copyright law. Copyright, IPR and Moral Rights for the works on this site are retained by the individual authors and/or other copyright owners. Terms and conditions for use of this material are defined in the policies page.

\section{CLoK}

Central Lancashire online Knowledge www.clok.uclan.ac.uk 
A Changing Culture? Qualitative Methods Teaching in UK Psychology

\author{
Stephen Gibson
}

York St John University

Cath Sullivan

University of Central Lancashire

Stephen Gibson, School of Psychological \& Social Sciences, York St John University, UK; Cath Sullivan, School of Psychology, University of Central Lancashire, UK.

Correspondence concerning this article should be addressed to Stephen Gibson,

School of Psychological \& Social Sciences, York St John University, Lord Mayor's Walk, York, YO31 7EX, UK. E-mail: s.gibson@yorksj.ac.uk may not exactly replicate the authoritative document to be published in the APA journal. Please do not copy or cite without authors' permission. 


\begin{abstract}
This paper surveys the landscape of qualitative methods teaching in UK psychology. First, we provide an overview of the administrative framework for this teaching, and highlight the positive development that is the stipulation by key national bodies that undergraduate psychology programmes should teach qualitative methods. Second, we discuss an attempt to meet the needs for training and resources that resulted from these stipulations, as well as noting how recent changes in the higher education funding landscape have made it more difficult to meet these needs. Third, we review literature on the teaching of qualitative methods in UK psychology departments, and note the relative paucity of studies addressing this issue. In conclusion, we suggest that the key issue remains the stubbornness of the 'quantitative culture' in many departments. The official bureaucratic infrastructure of UK psychology teaching may now mandate that qualitative methods be taught, but the tentative conclusions that can be drawn from what literature there is suggest that this obscures a variety of practices at the departmental level, with many programmes still providing little more than tokenistic engagement with qualitative methods.
\end{abstract}

Keywords: pedagogy, qualitative methods, teaching, UK Association. This paper is currently in press has not yet been published. This paper is not the copy of record and may not exactly replicate the authoritative document to be published in the APA journal. Please do not copy or cite without authors' permission. 
A Changing Culture? Qualitative Methods Teaching in UK Psychology

The landscape of qualitative psychology teaching in the UK has changed substantially over the last few decades. A major success has been the continued inclusion of qualitative psychology in subject benchmarks and accreditation criteria. In this paper we will consider the current context and make recommendations about how best to build upon this success. First we provide an overview of the regulatory and policy frameworks that are the backdrop for qualitative methods ${ }^{1}$ teaching in the UK. We then highlight some initiatives that have helped to embed qualitative methods teaching into the psychology curriculum. We focus particularly on one initiative, a working group that has existed since 2005 under the auspices of a number of umbrella organisations - most recently finding a home within the Qualitative Methods in Psychology (QMiP) Section of the British Psychological Society (BPS). This working group provides resources, training and a forum for sharing good practice for teachers of qualitative methods on UK psychology degrees. Finally, we review evidence from research that has mapped the nature and extent of qualitative methods teaching in the UK, together with smaller-scale studies that specify in more detail aspects of this teaching. We argue that while there are clear signs of substantial progress, there remain areas of UK psychology that still fail to recognise the role and importance of qualitative research methods. This has two major consequences. First, where it leads to a failure to fully integrate qualitative methods into the curriculum, it produces teaching that does not fully reflect the nature of the discipline. Second, this prevents our research methods training from equipping

\footnotetext{
${ }^{1}$ King and Horrocks (2010) make a useful distinction between method and methodology, with the former referring to tools for the collection of data, and the latter referring to the conceptual and philosophical perspectives that inform how methods are used. For economy of exposition, in the present article we use the phrase 'qualitative methods' to refer to both method and methodology.

Authors' final version accepted for publication in Qualitative Psychology on 28/5/17. CAmerican Psychological Association. This paper is currently in press has not yet been published. This paper is not the copy of record and may not exactly replicate the authoritative document to be published in the APA journal. Please do not copy or cite without authors' permission.
} 
psychology graduates with a sufficiently broad range of research methods skills to engage with the world into which they graduate.

\section{The UK context for teaching qualitative methods in undergraduate degree programmes}

UK scholars have been at the forefront of the rapid development of qualitative methods in psychology over recent years. Some of the first textbooks on qualitative methods in psychology came from the UK (e.g., Banister et al, 1994; Richardson, 1996), and these have been followed by a range of comprehensive and innovative texts (e.g. Forrester, 2010; Howitt, 2013; Lyons \& Coyle, 2016; Smith, 2015; Sullivan, Gibson \& Riley, 2012; Willig, 2013). Furthermore, landmark publications such as the Sage Handbook of Qualitative Research in Psychology (Willig \& Stainton Rogers, 2008) and the five volume anthology Qualitative Research in Psychology (Gough, 2014) have been edited in the UK. At the same time, the institutional and bureaucratic infrastructure of the discipline in the UK has undergone notable shifts towards the inclusion and recognition of qualitative research methods over the last two decades.

Undergraduate psychology degrees in the UK have two key 'benchmarks' against which they are typically assessed, for example when institutions are seeking to develop a new degree programme. The first is the subject benchmark statement provided by the Quality Assurance Agency (QAA). The QAA is the national body for the monitoring of educational standards within UK universities, and publishes benchmark statements for many disciplines.

The benchmark statement for psychology is currently under review, but at the time of writing (March 2017) the current version makes specific mention of qualitative methods as an area that must be covered, and includes the following clarification on how this should be interpreted: 
'It should be noted that qualitative methods are understood broadly here, and might include consideration of procedures of data gathering, such as interviewing and participant observation, as well as associated methods of analysis; for example, discourse analysis, grounded theory and conversation analysis.'

(QAA, 2010, p. 5)

This represents a development of the original benchmarking statement, published in 2002, which stated that qualitative methods 'might include protocol analysis, interviews, grounded theory and discourse analysis' (QAA, cited in Forrester \& Koutsopolou, 2008, p. 174).

The second key 'benchmark' for UK undergraduate psychology programmes is the BPS curriculum for accredited programmes. This is of vital importance because BPS accreditation is crucial for the wider recognition of psychology qualifications. For example, having a BPS accredited undergraduate degree is important for students wishing to gain access to training for the chartered psychology professions, such as clinical, forensic and educational psychology. Qualitative methods were added to the curriculum in 2004 (Sullivan, Holyoak \& Willan, 2009), and the most recent version of the curriculum maintains the requirement to cover qualitative methods. One of the skills that programmes are required to equip graduates with is the ability to 'reason analytically and demonstrate competence in a range of quantitative and qualitative methods' (BPS, 2016, p. 17). The curriculum - which draws heavily on the QAA benchmark statement - also specifies observation, interviews and focus groups as methods that students should gain practical experience of, and stipulates that they should be able to 'analyse, present and evaluate quantitative and qualitative data and evaluate research findings' (p. 20).

The growing recognition of qualitative methods in UK psychology led in 2005 to the establishment of the QMIP Section of the BPS (see Madill, 2015, for a recent account of QMIP's formation). QMIP immediately became the BPS's largest Section and, at the time of Association. This paper is currently in press has not yet been published. This paper is not the copy of record and may not exactly replicate the authoritative document to be published in the APA journal. Please do not copy or cite without authors' permission. 
writing, still is. Despite this, the requirement to teach qualitative methods has posed a challenge for many departments, especially those that do not have the relevant expertise in qualitative approaches (Trapp, Banister, Ellis, Latto, Miell \& Upton, 2011). In this context, the Higher Education Academy (HEA) Psychology Network set up a working group in 2005 to develop resources for teachers of qualitative research methods (Forrester, 2006; Forrester \& Koutsopoulou, 2008). This group - initially known as the Teaching Qualitative Research Methods at Undergraduate Level (TQRMUL) working group, and subsequently as the Teaching Qualitative Psychology (TQP) group - has become a focal point for much of the work around teaching qualitative methods in the UK.

\section{The TQRMUL/TQP group}

The HEA is a publically-funded organization which promotes teaching and learning in UK higher education. Until 2011, the HEA included subject centres which aimed to support teaching and learning within particular disciplines. The subject centre for psychology, called the Psychology Network, was based in the Department of Psychology at the University of York and headed by Annie Trapp. The TQRMUL group was established in 2005 with the aim of providing resources and training for teachers of qualitative methods (Sullivan, 2015). Chaired by Mike Forrester from 2005-2008, and by Stephen Gibson from 2008-2011, the group ran annual workshops, developed a range of web resources, produced two textbooks (Forrester, 2010; Sullivan, Gibson \& Riley, 2012) and a special issue of the journal Psychology Learning and Teaching (Gibson \& Sullivan, 2012). A major part of the rationale for setting up TQRMUL was that academics were being asked to teach qualitative methods despite not being qualitative researchers themselves, and this was confirmed in the workshops, which attracted many delegates who had little or no experience of using qualitative methods. Indeed, although current guidelines on postgraduate research training Association. This paper is currently in press has not yet been published. This paper is not the copy of record and may not exactly replicate the authoritative document to be published in the APA journal. Please do not copy or cite without authors' permission. 
issued by the main funder of UK social science doctorates, the Economic and Social Research Council (ESRC), stipulate that all social scientists should receive training in both quantitative and qualitative methods (ESRC, 2015), the majority of staff will have trained before the introduction of such requirements. In this respect, one of the key TQRMUL resources was a dataset, freely available on the internet, which was created specifically for the purpose of being used as a teaching resource. The TQRMUL dataset consists of video recordings and transcripts of five semi-structured interviews on the topic of 'friendship' (Gibson, 2010). These materials have been used widely - at the time of the Psychology Network's closure in 2011 the materials had been downloaded over 60,000 times - and formed the basis of one of the textbooks developed by members of the group (Forrester, 2010). This dataset is still being used for teaching qualitative research methods within and beyond the UK, and work is now underway on a second edition of the textbook that uses the dataset.

The HEA and its subject centres arose at a time when higher education was relatively well-resourced in the UK. However, with the financial crisis and the subsequent policy of austerity adopted by the Conservative-Liberal Democrat coalition government formed in 2010, the landscape changed and the subject centres were closed. This left only the central HEA, despite the consensus in the sector seeming to suggest that it was the subject centres that were most valued (Attwood, 2010). The renamed TQP group continued as a 'special interest group' of the HEA from 2011 with Cath Sullivan as the Chair, before joining with the QMIP Section of the BPS in 2015 (Sullivan, 2015) following a further re-organization within the HEA. In this guise, and now Chaired by Leanne Etheridge, the group continues to run workshops and develop resources, although the reduction in available funding since 2011 is a cause for concern and will make it more difficult to develop resources such as the TQRMUL dataset in future. In the early days of the workshops run by this group, there was some Association. This paper is currently in press has not yet been published. This paper is not the copy of record and may not exactly replicate the authoritative document to be published in the APA journal. Please do not copy or cite without authors' permission. 
subsidy from the HEA, which helped to make attendance at workshops more cost-effective for those attending. However, the current funding context is such that workshops are more likely to need to be at least able to 'break even' financially. The training needs that arose after the initial inclusion of qualitative methods in the QAA subject benchmark statement have been met to some extent, but there is a continuing need for training that will be harder to provide given the challenges of finding sufficient time and resources.

Thus far we have considered the extent to which the requirement to teach qualitative methods has been embedded in the policy and accreditation context of psychology courses in UK universities, and the TQP group, which has provided training and support for lecturers. However, the actual evidence base concerning the teaching of qualitative methods is still developing, and it is this literature that we consider next.

\section{Literature on teaching qualitative methods in psychology in the UK}

There is a healthy literature on the teaching of qualitative methods - Chenail's (2010) bibliography gives a sense of the breadth of the field. However, when one focuses specifically on the teaching of qualitative methods in psychology, let alone when one focuses specifically on the UK context, the picture becomes much less clear. While there are notable exceptions, the evidence base remains limited. This is not to suggest that research on teaching qualitative methods in other disciplines is of no value for psychology, but rather to acknowledge that specific disciplinary histories have given rise to divergent traditions of qualitative work across the social sciences. Existing UK research on teaching qualitative research methods in psychology can (broadly speaking) be placed into two groups: First are case studies and small-scale evaluation studies which provide an overview of the way in which qualitative methods - or a particular aspect of qualitative methods - are taught in specific contexts (e.g. in a single department). Second are a smaller group of studies which Association. This paper is currently in press has not yet been published. This paper is not the copy of record and may not exactly replicate the authoritative document to be published in the APA journal. Please do not copy or cite without authors' permission. 
aim to capture a broader picture (e.g., through surveys) of the way in which qualitative methods are taught across departments.

\section{Case studies and small-scale evaluation studies}

A number of articles providing an overview of a particular way in which the authors teach qualitative methods have appeared in recent years (e.g. Burr \& King, 2012; Fielden, Goldie, \& Sillence, 2012; Hill \& Brunsden, 2008; Mason, 2002; Owen \& Riley, 2012; Wiggins \& Forrest, 2005; Wiggins \& Burns, 2009). For example, Wiggins and Burns (2009) outline a problem-based learning approach to teaching qualitative research methods, and explain how this was implemented and evaluated in one university department. Maunder, Gordon-Finlayson, Callaghan and Roberts (2012) outline an approach to the supervision of qualitative Master's theses grounded in Wenger's idea of 'communities of practice', and explore how this was put into practice at their institution.

Research like this, which draws on pedagogical theory and research to inform and reflect upon teaching developments, has offered useful insights into the practice of teaching qualitative methods in UK psychology. For example, studies have illustrated the usefulness of reflexive practice (e.g., Sargeant, 2012), have detailed innovative ways of helping students to learn about qualitative methods (e.g., Burr and King, 2012) and have provided insights into some of the challenges of helping students gain deep understanding of some of the concepts that come along with qualitative research (e.g., Sargeant, 2012). These studies also provide some evidence that, to be successful, qualitative methods teaching needs to be integrated well with other aspects of research methods teaching (Fielden, Goldie and Sillence, 2012). This raises a key issue that links with training needs, as discussed above. Anecdotal evidence (e.g. feedback from training workshops) suggests that qualitative research is still often taught by a relatively small number of specialist staff within UK psychology departments. This is a 
challenge in terms of being able to teach students about a range of qualitative approaches as the expertise of staff may not cover the full range of qualitative methods. Somebody who is very confident teaching conversation analysis, for example, may not necessarily also be a specialist in phenomenological analysis, just as a person who is a specialist in meta-analysis may not be a specialist in structural equation modelling. Furthermore, this suggests that a key challenge for the future is to ensure that qualitative and quantitative methods of analysis are taught in an integrated way that is embedded in the context of more general research methods topics such as ethics, epistemology, quality and research design.

Studies like those discussed above provide a useful body of case studies that detail some of the ways in which qualitative methods are being taught, which is a useful resource for current practitioners. However, research that considers the broader teaching landscape is also important for trying to understand the context within which these case studies are done.

\section{Surveys}

Three studies have sought to survey the landscape of UK qualitative methods teaching in recent years, all of which have focussed on undergraduate teaching (Forrester and Koutsopoulou, 2008; Hugh-Jones, Madill, Gibson, Keane \& Beestin, 2012; Wiggins, Gordon-Finlayson, Becker \& Sullivan, 2015). Taken individually, each of these studies is limited in one way or another, yet taken together it is possible to draw some tentative conclusions concerning the nature of qualitative methods teaching over the last decade or so in the UK.

Forrester and Koutsopoulou (2008) conducted a survey to ascertain the nature and type of qualitative methods teaching undertaken on UK undergraduate psychology degree programmes. Eighteen out of 113 psychology departments responded to the survey, making it difficult to establish anything like a national picture of qualitative methods teaching, but Association. This paper is currently in press has not yet been published. This paper is not the copy of record and may not exactly replicate the authoritative document to be published in the APA journal. Please do not copy or cite without authors' permission. 
nevertheless highlighting some salient issues ${ }^{2}$. For example, Forrester and Koutsopoulou found that qualitative methods were taught mostly in the first and second years of degree programmes, with around six hours of coverage during the first year and 15 hours in the second year. Much of this was large-group teaching (groups of 100 or more students), although some smaller workshop-style classes were often also used in second year. Data collection methods covered included interviews, observations, verbal protocols and recordings of everyday conversations. Particular approaches to qualitative research covered by respondents included grounded theory, interpretative phenomenological analysis (IPA), protocol analysis, thematic analysis, discourse analysis and conversation analysis.

In an unpublished survey conducted for the BPS QMiP Section, Hugh-Jones et al (2012) sought to update Forrester and Koutsopoulou's (2008) survey. Hugh-Jones et al's survey was composed of two phases: an information-gathering exercise that used university websites as a source of data about the topics taught on particular courses; and a survey using telephone interviews to sample a total of 33 staff members (each from a different institution) with responsibility for qualitative methods teaching. The study again found that the second year of degree programmes was the peak year for qualitative methods teaching, with approaches such as discourse analysis, IPA, thematic analysis and grounded theory being most widely taught. Thematic analysis of interview responses suggested, amongst other things, that the changes in the BPS curriculum had instigated a sea-change in the incorporation of qualitative methods into departments' research methods courses. Respondents also identified lack of sufficient time allocated to qualitative methods in the

\footnotetext{
${ }^{2}$ There are other complicating factors in treating the UK as a single 'national' context, not least the differences between higher education systems in the UK's constituent nations. For example, the typical undergraduate degree in Scotland is four years in duration, whereas in the rest of the UK it is three years.

Authors' final version accepted for publication in Qualitative Psychology on 28/5/17. CAmerican Psychological Association. This paper is currently in press has not yet been published. This paper is not the copy of record and may not exactly replicate the authoritative document to be published in the APA journal. Please do not copy or cite without authors' permission.
} 
curriculum as an impediment to teaching, as well as a lack of staff with appropriate expertise to teach them. This further supports the point made above about the challenges of covering a range of qualitative methods topics at the undergraduate level. Also, if qualitative methods are still given a substantially smaller proportion of space in research methods teaching (as allowed by the relevant subject benchmarks), this potentially undermines the goal of ensuring that qualitative methods are appropriately valued in the curriculum.

Beyond the issue of resources and time, many interviewees also suggested that quantitative methods teaching was so deeply entrenched in the culture of psychology departments that even undergraduate students in the early stages of their education were socialized into a hypothetico-deductive approach to psychology that constituted a lens through which they subsequently viewed qualitative methods. This was reflected also in the articulation of a culture of marginalisation in which many respondents argued that qualitative methods were still considered as very much second best in comparison to experimental methodology and statistical analysis, and in some cases respondents had experienced overt undermining by non-qualitative colleagues.

In contrast to Forrester and Koutsopoulou (2008) and Hugh-Jones et al (2012), Wiggins et al's (2015) survey focussed not on providing a broad overview of qualitative methods teaching but rather on the specific issue of how qualitative dissertations (undergraduate theses) are supervised. Typically, the undergraduate dissertation is seen as the pinnacle of research training on UK undergraduate courses and is often a large module with a higher credit value than any other module on the programme. Wiggins et al. note that little previous work had explored the process of supervising qualitative dissertations, with only the guidelines developed by Gough, Lawton, Madill and Stratton (2003; see also Madill, Gough, Lawton \& Stratton, 2005) serving as specific guidance for supervisors of qualitative projects. Gough et al's work, funded by the Learning and Teaching Support Network - a Association. This paper is currently in press has not yet been published. This paper is not the copy of record and may not exactly replicate the authoritative document to be published in the APA journal. Please do not copy or cite without authors' permission. 
forerunner of the HEA Psychology Network - had used a workshop featuring experienced dissertation supervisors as a starting point for the development of a set of broad principles for the supervision of qualitative projects. The aim was motivated in part by the need for a framework by which to evaluate qualitative dissertations, particularly in light of anecdotal evidence suggesting that qualitative projects were often misunderstood by non-qualitative markers and examiners who would use inappropriate criteria (e.g. sample size) as reasons for marking down qualitative work.

Wiggins et al conducted semi-structured interviews with 17 staff members responsible for supervising qualitative dissertations at universities in Scotland and North East England. These interviews were transcribed for content and analysed using thematic analysis (Braun \& Clarke, 2006). Three key themes were derived from the analysis: 1 . A sense that there was still a 'quantitative culture' in psychology departments; 2. A reliance on supervisory expertise; 3. An unwillingness of supervisors to leave their 'comfort zone'.

Wiggins et al's first theme is in many respects the key to understanding their findings, and indeed this relates most closely to issues identified time and again by authors in a variety of contexts: respondents said that their departments were typically marked by a culture which placed quantitative research as being better than qualitative research. This was manifested, for example, in disagreements between supervisors and second markers of dissertations who had less experience with qualitative research methods but who nevertheless sought to award lower marks simply because a project was qualitative. This is remarkably reminiscent of the state of affairs that Gough et al's (2003) guidelines set out to rectify. Supervisors argued that an imbalance in the amount of coverage afforded to qualitative and quantitative methods at earlier stages of the undergraduate degree meant that they were at a disadvantage when it came to supervising student dissertation projects. This led some students to devalue and mis-trust qualitative methods, and resulted in relatively low demand Association. This paper is currently in press has not yet been published. This paper is not the copy of record and may not exactly replicate the authoritative document to be published in the APA journal. Please do not copy or cite without authors' permission. 
for qualitative project supervision. As a result, qualitative supervision tended to rely heavily on the expertise of supervisors (Wiggins et al's second theme), with only limited support available. Supervisors thus argued that they remained in their comfort zone by tending to supervise only projects involving those approaches that they used themselves as there was a lack of training and support to offer a wider range of project options. Again, although it is likely that many more UK undergraduates are using qualitative methods in their dissertations than was the case even 10 years ago, this progress is potentially undermined by challenges around the status of qualitative methods and the resourcing that would allow supervision in a fuller range of methods to be offered.

One implication of this relates to the issue of the research methods skills that students are able to acquire. The importance of developing graduates' skills in qualitative research is acknowledged both by the QAA (2010) and the ESRC (2015). Psychology graduates are expected to have skills in the basic research methods of the discipline and clearly, if we use the BPS curriculum and the QAA benchmarking statement to define this, it includes qualitative methods. There remain question marks over the extent to which psychology graduates are fully equipped with both quantitative and qualitative methodological skills, and as such there is still work to do to ensure that the expectations of key bodies - including those, such as the ESRC, which fund our graduates to do doctoral research - are met. Given the extent to which the evidence base underpinning a range of career pathways - both within psychology and beyond (e.g. health, education) - draws on quantitative, qualitative and mixed-methodological work, we open up a broader range of opportunities to our graduates when we equip them with both qualitative and quantitative research skills.

\section{Conclusions}

Authors' final version accepted for publication in Qualitative Psychology on 28/5/17. CAmerican Psychological Association. This paper is currently in press has not yet been published. This paper is not the copy of record and may not exactly replicate the authoritative document to be published in the APA journal. Please do not copy or cite without authors' permission. 
Our overview of the landscape of qualitative methods teaching in psychology in the UK highlights the relatively patchy state of the evidence base concerning what is covered in qualitative methods teaching, how it is taught and what additional support/resource needs there are. However, in drawing together what work there is we can somewhat cautiously proceed to some tentative conclusions:

1. There has been a great deal of progress in recent years, but there is still room for improvement. Subject benchmarks continue to include qualitative methods, work has gone into training and the development of resources to support this area (there are now, for example, many more textbooks available and online resources have proliferated). However, there is still some way to go before qualitative methods are seen as being on an even footing with quantitative methods. As Wiggins et al (2015) note, it is disappointing that interviewees in their study identified a broadly similar 'quantitative culture' as had been identified in participants in Gough et al's workshop over a decade earlier. Continued work is needed to effect cultural change. There is always a tension between remaining outside a system and seeking to critique it in the hope of forcing change, and working within a system in an attempt to change it from the inside. In reality, both are probably needed but it is a clear lesson from the UK experience that in order to effect change, qualitative psychologists need to get themselves into positions where they are able to influence how the discipline is taught. This means that qualitative psychologists might volunteer to co-ordinate research methods modules, and to lead degree programmes, in order to ensure that an appropriate balance is struck in the teaching of different methodologies. Those wishing to make a difference could also put themselves forward to sit on hiring panels in an attempt to counter any bias against qualitative psychology, and work towards positions of leadership in order to influence the culture and direction of their 
departments. In some circumstances, such attempts may be met with resistance, but the utility of taking action to improve the breadth and quality of teaching in our discipline should not be underestimated.

2. Institutional support through professional frameworks is important. It seems that the inclusion of qualitative methods in the BPS's curriculum for accredited undergraduate degree programmes has made a genuine difference to the status of qualitative methods teaching in UK psychology departments. Clearly it is still considered inferior in some departments, and as such its coverage in the curriculum may be little more than tokenistic, but in making it clear that qualitative methods must be taught, the BPS has reinforced the message that qualitative methods are an integral part of the discipline that all students should be exposed to. Allied to this, the founding of the QMIP Section within the BPS highlights the popularity of qualitative methods within the UK psychology community, and means there is a body that protects and enhances the role of qualitative methods within the BPS and in UK psychology more broadly. The lesson to draw from this is to engage with professional bodies and to seek to influence them, as has recently been the case in US context with the foundation of the Society for Qualitative Inquiry in Psychology and its incorporation into the American Psychological Association.

3. Fuller acknowledgment of the breadth of qualitative research is needed. The phrase 'qualitative methods' covers the teaching of a variety of approaches which are quite different, and in some cases fundamentally incompatible. While it may be politically expedient to treat these approaches as a coherent whole for some purposes (for example, to speak with a single voice to influence professional bodies), it is misleading to suggest that qualitative methods teaching forms a coherent whole in the same way that the standard canon of statistical analyses covered on undergraduate 
psychology programmes might do. Having said this, certain influential approaches can be identified time and again as featuring heavily in many institutions' teaching, most notably discourse analysis, IPA and - especially since the publication of Braun and Clarke's (2006) seminal paper - thematic analysis.

4. The links between teaching qualitative methods and other areas of research methods need to be addressed. There is evidence that research methods teaching still prioritises quantitative methods in many departments and so students are often coming to qualitative methods as 'the bit where things are different'. This creates challenges in helping students to become aware of the true breadth of the discipline. If qualitative and quantitative methods are too separate, one might argue that this could make it difficult to teach over-arching research methods topics in a truly integrated way. We believe that dialogue about the linkages in these areas would be useful for helping to ensure high quality research methods teaching.

5. Greater provision of resources to support teaching is required. There are arguably two key related problems here. First, there is relatively little financial support available for the creation of high quality educational resources. The HEA Psychology Network was an exception insofar as it funded such projects, but it is notable that this organization was a victim of budget cuts at precisely the time when the government was claiming to be creating a higher education funding system that placed students firmly at the centre. Second, there are limited incentives for academics to produce teaching materials intended for wider dissemination than simply for use in their own teaching. The continued primacy of research in appointment and promotion decisions means that pedagogical work generally takes a back seat and is typically the preserve of a relatively small group of individuals. In order to provide students with a comprehensive set of research skills, and to accurately reflect the nature of the 
discipline, those responsible for running programmes in psychology need to adequately resource this area of teaching.

In many respects, the first conclusion we identify is the most important. Until the slow and difficult process of culture change is more advanced, finding space for qualitative methods in the curriculum will always be difficult in many departments. A key challenge identified by several authors (e.g. Clarke \& Braun, 2013; Hill \& Brunsden, 2008; Wiggins et al, 2015) is the continuing assumption that broadly (post-)positivist epistemologies, emphasising hypothesis testing, experimental methodology and statistical analysis, continue to be considered the norm from which other methodological frameworks depart. For many teachers of qualitative methods, therefore, overcoming students' initial enculturation into the view that hypothetico-deductivism constitutes the best way of doing psychological research represents the starting point for qualitative methods teaching. As Clarke and Braun (2013, pp. 120-121) argue,

When we introduce students to the assumptions and values of qualitative research, we can start off back-footed; we also have to teach them that there is more than one way to do research within psychology, and that qualities such as subjectivity do not produce bias that undermines the research, but are essential to good qualitative research practice.

Indeed, examples of the 'quantitative culture' are not difficult to find, even in the very documents that have been instrumental in enabling qualitative methods to gain a foothold in the undergraduate curriculum. For instance, the BPS's (2010) guidance for departments undergoing accreditation includes many of the stipulations concerning the inclusion of qualitative methods outlined above, yet elsewhere in the document there is slippage into the assumption that hypothetico-deductivism is pre-eminent. For example, in a section entitled 'Promoting psychology as a science', it is suggested that the development of students-asAssociation. This paper is currently in press has not yet been published. This paper is not the copy of record and may not exactly replicate the authoritative document to be published in the APA journal. Please do not copy or cite without authors' permission. 
researchers 'affords a thorough scientific education based on experimental approaches, practical scientific teaching, and the associated transferable skills' (p. 10, italics added). Some might argue that privileging quantitative research methods is justifiable, as they are still more commonly used in psychological research. Others may argue that it is legitimate to give less space to qualitative methods on the undergraduate curriculum because it has less potential for being rated highly in the UK Research Excellence Framework (REF), the process by which research quality in UK universities is judged and which has consequences for reputation, funding and career success. However, an analysis of the most recent REF indicates that when qualitative psychological research is submitted to REF panels (sometimes to panels other than the psychology panel) it has the capacity to meet REF quality criteria and is not automatically deemed to be less useful than quantitative research (Riley, 2016). It seems that the issue is not so much that REF panels do not value qualitative psychology and more that psychology departments believe, falsely, that the REF will not value this research and therefore do not submit it (Riley, 2016). There is also some evidence from the last REF that qualitative research in health areas has great potential for applied impact that can make valuable contributions to policy and practice both nationally and internationally (Flowers, 2015). Consequently, the idea that it is legitimate to prioritise quantitative methods as foundational to psychology is becoming ever more difficult to defend.

Therefore, the failure to acknowledge qualitative methods as a normal and essential part of the discipline hardly seems a promising basis on which to teach research methods. Instead, courses should proceed from the assumption that there are multiple ways in which to do psychological research, and that there is more than one 'scientific method'. Debates between these approaches are to be encouraged, but starting off with a set of basic concepts that are derived from hypothetico-deductivism (e.g. hypothesis testing; experimentation; 
reliability; generalizability; etc.) and then mapping out how qualitative methods differ from these should no longer be an option.

Authors' final version accepted for publication in Qualitative Psychology on 28/5/17. CAmerican Psychological Association. This paper is currently in press has not yet been published. This paper is not the copy of record and may not exactly replicate the authoritative document to be published in the APA journal. Please do not copy or cite without authors' permission. 


\section{References}

Attwood, R. (2010, November 25). Academics express 'profound consternation' at supportcentre closures. Time Higher Education. Retrieved from https://www.timeshighereducation.com/news/academics-express-profoundconsternation-at-support-centre-closures/414393. article?storycode=414393

Banister, P., Burman, E., Parker, I., Taylor, M. \& Tindall, C. (1994). Qualitative methods in psychology: A research guide. Milton Keynes: Open University Press.

Braun, V., \& Clarke, V. (2006). Using thematic analysis in psychology. Qualitative Research in Psychology, 3, 77-101. doi: 10.1191/1478088706qp063oa

British Psychological Society. (2010). Accreditation through partnership handbook: Guidance for undergraduate and conversion psychology programmes. Retrieved from

http://www.bps.org.uk/sites/default/files/documents/undergraduate_accred2010_web. pdf

British Psychological Society. (2016). Standards for the accreditation of undergraduate, conversion and integrated Masters programmes in psychology. Retrieved from http://www.bps.org.uk/system/files/Public\%20files/PaCT/Undergraduate\%20Accredit ation\%202016_WEB.pdf

Burr, V., \& King, N. (2012). 'You're in cruel England now!': Teaching research ethics through reality television. Psychology Learning and Teaching, 11, 22-29. doi: 10.2304/plat.2012.11.1.22

Chenail, R. J. (2010). Teaching and learning qualitative research and qualitative research design resources. Retrieved from http://www.nova.edu/ssss/QR/Teaching_042610.pdf 
Clarke, V., \& Braun, V. (2013). Methods: Teaching thematic analysis. The Psychologist, 26, 120-123.

Economic and Social Research Council. (2015). ESRC postgraduate training and development guidelines. ( $2^{\text {nd }}$ Ed.). Retrieved from http://www.esrc.ac.uk/files/skillsand-careers/studentships/postgraduate-training-and-development-guidelines-2015/

Fielden, A. L., Goldie, S., \& Sillence, E. (2012). Taking another look: Developing a sustainable and expandable programme of qualitative research methods in psychology. Psychology Learning and Teaching, 11, 46-51. doi: 10.2304/plat.2012.11.1.46

Flowers, P. (2015, September). Delivering impact through qualitative methods: Gay men and HIV testing. Paper presented at the BPS QMiP Section Annual Conference, Cambridge, UK.

Forrester, M. (2006). Teaching qualitative research methods at undergraduate level. QMIP Newsletter, 1, 7-8.

Forrester, M. A. (Ed.). (2010). Doing qualitative research in psychology: A practical guide. London: Sage.

Forrester, M. A., \& Kousopoulou, G. Z. (2008). Providing resources for enhancing the teaching of qualitative methods at the undergraduate level: Current practices and the work of the HEA Psychology Network group. Qualitative Research in Psychology, 5, 173-183. doi: 10.1080/14780880802314312

Gibson, S. (2010). Introducing the dataset. In M. A. Forrester (Ed.), Doing qualitative research in psychology: A practical guide (pp. 121-134). London: Sage.

Gibson, S., \& Sullivan, C. (2012). Teaching qualitative research methods in psychology: An introduction to the special issue. Psychology Learning and Teaching, 11, 1-5. doi: 10.2304/plat.2012.11.1.1 may not exactly replicate the authoritative document to be published in the APA journal. Please do not copy or cite without authors' permission. 
Gough, B. (Ed.). (2014). Qualitative research in psychology (Vols. 1-5). London: Sage.

Gough, B., Lawton, R., Madill, A., \& Stratton, P. (2003). Guidelines for the supervision of undergraduate qualitative research in psychology. York: LTSN Psychology.

Hill, R., \& Brunsden, V. (2008). Teaching IPA: Emphasising intuition over theory. Social Psychological Review, 10, 31-35.

Howitt, D. (2013). Introduction to qualitative methods in psychology ( $2^{\text {nd }}$ ed.). Harlow: Pearson.

Hugh-Jones, S., Madill, A., Gibson, S., Keane, K., \& Beestin, L. (2012). A national survey of qualitative research methods teaching in UK HE psychology departments. Retrieved from https://www.academia.edu/8483353/HughJones_S._Madill_A._et_al._2012_._A_national_survey_of_qualitative_research_meth ods_teaching_in_UK_HE_psychology_departments._QMiP_Report

King, N., \& Horrocks, C. (2010). Interviews in qualitative research. London: Sage.

Lyons, E., \& Coyle, A. (2016). Analysing qualitative data in psychology (2 ${ }^{\text {nd }}$ ed.). London: Sage.

Madill, A. (2015). Let a thousand flowers bloom. The Psychologist, 28, 656-658.

Madill, A., Gough, B., Lawton, R., \& Stratton, P. (2005). How should we supervise qualitative projects? The Psychologist, 18, 616-618.

Mason, O. J. (2002). Teaching qualitative research methods: Some innovations and reflections on practice. Psychology Teaching Review, 10, 68-75.

Maunder, R. E., Gordon-Finlayson, A., Callaghan, J., \& Roberts, A. (2012). Behind supervisory doors: Taught Master's dissertation students as qualitative apprentices. Psychology Learning and Teaching, 11, 30-38. doi: 10.2304/plat.2012.11.1.30 may not exactly replicate the authoritative document to be published in the APA journal. Please do not copy or cite without authors' permission. 
Owen, C., \& Riley, S. (2012). Teaching visual methods using performative storytelling, reflective practice and learning through doing. Psychology Learning and Teaching, 11, 60-65. doi: 10.2304/plat.2012.11.1.60

Quality Assurance Agency. (2010). Subject benchmark statement: Psychology ( $3^{\text {rd }}$ ed.). Retrieved from http://www.qaa.ac.uk/en/Publications/Documents/Subject-benchmarkstatement-Psychology.pdf

Richardson, J. T. E. (Ed.). (1996). Handbook of qualitative research methods for psychology and the social sciences. Oxford: BPS Blackwell.

Riley, S. (2016). What does REF mean for qualitative psychologists? QMiP Bulletin, 21, 5-7. Sargeant, S. (2012). 'I don't get it': A critical reflection on conceptual and practical challenges in teaching qualitative methods. Psychology Learning and Teaching, 11, 39-45. doi: 10.2304/plat.2012.11.1.39

Smith, J. A. (Ed.). (2015). Qualitative psychology: A practical guide to research methods ( $3^{\text {rd }}$ ed.). London: Sage

Sullivan, C. (2015). Teaching qualitative psychology group (TQPG) joins the Qualitative Methods in Psychology Section of the British Psychological Society. QMIP Bulletin, 19, 20-21.

Sullivan, C., Gibson, S., \& Riley, S. (Eds.). (2012). Doing your qualitative psychology project. London: Sage.

Sullivan, C., Holyoak, L., \& Willan, V. J. (2009). Accreditation of undergraduate psychology courses at the University of Central Lancashire under the 2004 British Psychological Society syllabus: Implications for the teaching of qualitative research methods. QMIP Newsletter, 7, 35-41.

Trapp, A., Banister, P., Ellis, J., Latto, R., Miell, D., \& Upton, D. (2011). The future of undergraduate psychology in the United Kingdom. York: Higher Education 
Academy Psychology Network. Retrieved from

http://www.bps.org.uk/sites/default/files/documents/the_future_of_undergraduate_psy chology_in_the_uk.pdf

Wiggins, S., \& Burns, V. (2009). Research methods in practice: The development of problem-based learning materials for teaching qualitative research methods to undergraduate students. Psychology Learning and Teaching, 8, 29-33. doi: 10.2304/plat.2009.8.1.29

Wiggins, S., \& Forrest, S. (2005). Integrating quantitative and qualitative approaches in psychology research methods teaching: The example of a classroom debate. Psychology Learning and Teaching, 4, 90-94. doi: 10.2304/plat.2004.4.2.90

Wiggins, S., Gordon-Finlayson, A., Becker, S., \& Sullivan, C. (2015). Qualitative undergraduate project supervision in psychology: Current practices and support needs of supervisors across North East England and Scotland. Qualitative Research in Psychology, 13, 1-19. doi: 10.1080/14780887.2015.1075641

Willig, C. (2013). Introducing qualitative research in psychology. Maidenhead: Open University Press.

Willig, C., \& Stainton Rogers, W. (Eds.). (2008). The Sage handbook of qualitative research in psychology. London: Sage. may not exactly replicate the authoritative document to be published in the APA journal. Please do not copy or cite without authors' permission. 